\title{
Supportive adult relationships and the academic engagement of Latin American immigrant youth ${ }^{\text {t3 }}$
}

\author{
Gillian Green ${ }^{\text {a }}$, Jean Rhodes ${ }^{\mathrm{a}, *}$, Abigail Heitler Hirsch ${ }^{\mathrm{a}}$, \\ Carola Suárez-Orozco ${ }^{b}$, Paul M. Camic ${ }^{\mathrm{c}}$

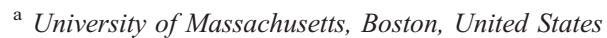 \\ ${ }^{\mathrm{b}}$ New York University, United States \\ c Canterbury Christ Church University, United Kingdom
}

Received 21 December 2006; received in revised form 8 June 2007; accepted 2 July 2007

\begin{abstract}
The central aim of this study was to explore the academic engagement trajectories of a sample of recently arrived immigrant students from Latin America. Using an analytic framework that can dynamically model time-sensitive fluctuations (HLM; [Raudenbush, S. W., \& Bryk, A. S. (2002). Hierarchicical Linear Models: Applications and Data Analysis Methods (2nd Edition ed.). Thousand Oaks, CA: Sage Publications]), we explored how initial engagement, gender, and support from caring adults at school shaped youths' engagement over time. Students reported a range of engagement trajectories, with gender and support emerging as important predictors of youths' engagement trajectories. Additionally, perceptions of support fluctuated from year to year, and these fluctuations were linked to youths' academic engagement. The findings point to associations between support perceptions and engagement, including links between students' current academic motivation and effort and their current connections with adults. Taken together, the findings present a nuanced portrait of academic engagement and suggest how relationships at school might facilitate positive academic adjustment among Latin American immigrant students over time. Implications for future research, public policy, and practice are discussed.

(C) 2007 Society for the Study of School Psychology. Published by Elsevier Ltd. All rights reserved.

Keywords: Immigrant youth; Teacher-student relationship; Academic engagement

\footnotetext{
This article was accepted under Dr. Pianta's editorship.

* Corresponding author. Tel.: +1 6172876368.

E-mail address: Jean.Rhodes@umb.edu (J. Rhodes).
}

0022-4405/\$ - see front matter (C) 2007 Society for the Study of School Psychology. Published by Elsevier Ltd. All rights reserved.

doi:10.1016/j.jsp.2007.07.001
\end{abstract}




\section{Introduction}

Latin American immigrant youth are the fastest growing sector of the U.S. youth population, increasing by $57 \%$ over the past decade (U.S. Census, 2000). The country's demographic shifts are mirrored in American classrooms, where there has been a dramatic influx of Latino students. Indeed, one-fifth of children in the U.S. are growing up in immigrant families, and $62 \%$ of these children are Latino (Hernandez, 2004). Although many Latino immigrants enter their schools engaged in learning and optimistic about their futures, their academic adjustment is precarious and vulnerable to change (Kao \& Tienda, 1998; Portes \& Rumbaut, 2001; Suárez-Orozco \& Suárez-Orozco, 2001). Indeed, while newcomer immigrant youth enjoy an initial advantage relative to their non-immigrant counterparts, length of residence in the U.S. has been associated with declines in students' academic achievement and aspirations (Suarez-Orozco \& Suarez-Orozco, 2001).

\section{Challenges and supports for Latin American immigrant youth}

Latin American origin immigrant youth and native-born Latino students are at risk for academic disengagement, which can result in failing grades, multiple absences, and eventually dropping out (Catterall, 1998; Fry, 2003; McMillan 1997; Rumbaut, 1994; Suárez-Orozco \& Suárez-Orozco, 2001; Suárez-Orozco, Suárez-Orozco, \& Todorova, 2007; Velez, 1989; Vernez \& Abrahamse, 1996; White \& Kaufman, 1997; U.S. Census, 2000). Although many immigrants face harmful stereotypes, prejudices, and discrimination, the 'negative social mirror' (Suárez-Orozco, 1987) that Latino immigrant youth encounter may be especially corrosive to academic engagement. Unlike some immigrant youth who may be classified as "model minorities" or whose fair skin allows them to "pass," Latino immigrant youth may be perceived as "illegals" lacking rights to "American" privileges including education (Portes, 2000; Suárez-Orozco, 2000). Prejudice and discrimination occurring outside of school-in the job market, workplace, and community-may also interfere with academic motivation and persistence. Latin American immigrant youth may find it more difficult to find Latino role models whose accomplishments (i.e. citizenship, hard work, and education) have been rewarded by equal treatment (Portes, 2000). With a decreasing sense of hope, Latin American immigrant youth may become less motivated to achieve and may withdraw emotionally and behaviorally from school (Coll, Crnic, Lamberty, \& Wasik, 1996; Ogbu, 1991; Portes, 1999; Suárez-Orozco, 2005; Vernez \& Abrahamse, 1996). Academic disengagement is particularly worrisome in light of the central importance of academic success to youths' adaptation in post-industrial nations (Portes \& Rumbaut, 2001).

Of course, not all Latin American immigrant youth fall prey to disengagement and school failure. Some remain actively involved or even increase their engagement over time. Others demonstrate fluctuating levels of engagement throughout their education. Indeed, students' academic engagement and disengagement is sensitive to contextual factors, including interpersonal connections forged at school. Supportive relationships with teachers and other school adults in particular have been found to contribute to the academic success of Latin American immigrant youth (Suárez-Orozco et al., 2007). In this study, we focus on the role of such support in predicting first generation Latin American immigrant 
students' engagement in school over a three-year period. To accommodate for variation in engagement and support at both the group-and individual-levels, we incorporate modeling techniques that assess the effects of support on engagement as both change over time.

The role of caring adults

Connections with caring teachers and adults at school can be an important protective factor in the lives of Latin American immigrant students. Adults at school offer information about cultural practices (Brewster \& Bowen, 2004; Cooper, Denner, \& Lopez, 1999; Stanton-Salazar \& Spina, 2003) and buffer the emotional stresses of language difficulties, exposure to discrimination, discomfort with other cultures, and family separations secondary to migration (Davison Aviles, Guerrero, Barajas Howarth, \& Thomas, 1999; Roffman, Suárez-Orozco, \& Rhodes, 2003; Romero \& Roberts, 2003; Suárez-Orozco \& Suárez-Orozco, 2001). Supportive school adults may provide positive social mirrors for Latin American immigrant youth, enhancing their pride in their ethnic and cultural backgrounds and affirming self-worth and competence (Suárez-Orozco, 1987). Importantly, school staff also affect students' peer relationships, shaping norms of behavior by setting cooperative goals, discouraging competition, and creating an ethos of mutual respect (Ryan \& Patrick, 2001). Finally, school staff may reach out to the other important adults in students' lives by holding culturally sensitive parent-teacher meetings and sending home instructive materials, thereby increasing parents' and guardians' involvement in their children's education.

A number of studies have shown that positive experiences with adults at school can set the stage for later academic engagement among Latino youth (Hamre \& Pianta, 2001; Roderick, 2003; Stanton-Salazar, Chavez, \& Tai, 2001). Teacher support is negatively associated with absences, detentions, and suspensions (Catterall, 1998; Hudley, Daoud, Polanco, Wright-Castro, \& Hershberg, 2003). Increases in teacher responsiveness have been associated with increases in Latino youths' confidence in graduating from high school, with the most vulnerable students showing the largest gains (Catterall, 1998; Valenzuela, 1999a). Croninger and Lee (2001) found that those students perceiving supportive teacher relationships were half as likely to drop out. Similarly, Roderick (2003) found that boys who graduated resembled their less fortunate peers in facing academic difficulties, but benefited from relationships with supportive adults at school that enabled them to push through hard times.

Unfortunately, Latin American immigrant youth often have limited access to supportive adults in schools. Schools serving immigrant populations tend to be affected by poverty, over-crowding, and segregation. Teachers and school staff are often ill-equipped with the specific skills (including bilingual education credentials) and knowledge needed to work with diverse students (Fry, 2003; Lowell \& Suro, 2002). In fact, Latin American immigrant youth in particular may have relationships with school adults that compromise their attachment to school. For example, studies have shown that teachers are less likely to praise and encourage Latino youth or to incorporate their ideas in class, as compared with youth of other ethnic backgrounds (Katz, 1999; Losey, 1995). Importantly, discrimination from teachers has been found to predict lower grades, academic self-concept and positive peer affiliation (Davison Aviles, Guerrero, Barajas Howarth, \& Thomas, 1999). Consequently, 
some have proposed that Latino youth rarely "drop out" of school; instead, they are "pushed out".

Previous research suggests that access to supportive relationships with school adults may also vary by gender. Latin American immigrant boys may experience less support from school staff, including stereotypes that are especially harmful to academic engagement; in addition, they may be more sensitive to the prejudices and disciplinary actions that regularly face them (Lopez, 2002; Suárez-Orozco, Qin-Hillard, Way, \& Chu, 2004; Valenzuela, 1999a,b). Moreover and perhaps related, Latin American immigrant boys have been found to be less likely than their female counterparts to seek help when experiencing academic setbacks or conflicts with school personnel. In part, such help-seeking may be at odds with culturally prescribed gender roles that discourage boys from showing vulnerability (Roderick, 2003; Stanton-Salazar 2001).

\section{Current study}

This study employed hierarchical linear modeling to examine students' perceptions of supportive school relationships as protective against academic disengagement over time. Previous studies of academic disengagement among immigrant students have tended to employ cross-sectional data, comparing two or more generations of cohorts, rather than addressing trajectories of change over time within the same cohort. Because most previous studies have included second- and sometimes even third-generation immigrants from a variety of origins (Fuligini \& Pederson, 2002; García-Coll, Szalacha, \& Palacios, 2005), they have been less able to explore initial adjustment patterns and the unique experiences of recently-arrived Latin American immigrant students. Additionally, prior work has been largely descriptive of youths' academic outcomes, with less attention to the underlying processes that might account for variation in adjustment, including change over time.

Statistical methods used to understand the nature and effects of perceived support on immigrant students' adjustment have often focused on correlational and mean-level analyses (e.g. regressions and multivariate analyses of variance). These statistical methods reflect the tacit assumptions that students who represent a wide range of adjustment experiences and who follow diverse trajectories can be meaningfully grouped together; moreover, they present a static picture of a period that is best characterized by heterogeneity and flux. Even studies benefiting from longitudinal designs typically have modeled baseline perceptions of school support onto changes in adjustment, resting on the notion that such perceptions remain stable over multiple years amidst changes in schools and teacher assignments. This view is valid only to the extent that perceptions of support actually reflect fixed, intrinsic qualities or characteristics of the student (e.g., attachment style, personality) (Pianta, Steinberg, \& Rollins, 1995).

While many theorists have, in fact, argued that support perceptions can be treated as relatively stable characteristics across providers and time (Lutz \& Lakey, 2001), this study draws from the theoretical perspective that support perceptions represent interactions among perceivers and their environments. As such, while adolescents may have some tendency to maintain global representations of relationships, their perceptions are also subject to new and changing relationships and contexts (Pianta, 1999; Pierce \& Lydon, 2001; Lakey, McCabe, Fisicaro, \& Drew, 1996). In addition, while some students are 
intrinsically more academically-orientated than others, academic engagement is also shaped by a variety of environmental factors, which themselves change over time.

Recognition of these complexities has increased in recent years and advanced statistical methods-including multilevel modeling (such as HLM) and structural equation modeling - have become popular approaches to studying youth over time. Such quantitative approaches have typically focused on native-born youth, however, and have rarely been applied to immigrant youth, including those from Latin America. For this reason, we chose an analytic framework (HLM; Raudenbush \& Bryk, 2002) that can dynamically model time-sensitive fluctuations. HLM is ideally suited for looking at longitudinal data where both independent and dependent variables fluctuate over time.

In this study, we tested three models, each of which examined a different facet of Latin American immigrant youths' engagement in school. The first model investigated trends in youths' engagement trajectories, describing change over time occurring at the group and individual levels, variation within the sample, and relationships between initial engagement and changes in engagement. We anticipated that students' engagement trajectories would show decreases over time at the group-level, but that there would be significant variation in these trajectories among the individuals within the group. Thus, some youth were expected to increase, others to decrease, and still others to maintain fairly constant levels of engagement during the three time points studied.

A second model predicted initial engagement and change in engagement over time with particular attention to gender and perceived support. In particular, we predicted that youth who perceived higher levels of support during the three years of the study would report more positive changes in engagement over time relative to youth who perceived lower levels of support. Within this context, girls were expected to evidence more positive changes in engagement than boys, although boys' engagement was expected to be more sensitive to perceptions of support.

Finally, a third model addressed relationships between year-to-year fluctuations in support and engagement in the group as a whole. Unlike the predictive model, which focused on associations between absolute, time-invariant levels of support and changing engagement, the third model addressed questions about associations between student-centered variation in support perceptions and engagement. Within-student variation in perceptions of support was expected to be positively associated with variation in engagement.

\section{Method}

\section{Procedures}

This study drew on a subset of the data that were collected through the Longitudinal Immigration Student Adaptation (LISA) study (Suárez-Orozco, \& Suárez-Orozco, 2001). The LISA study was a five-year longitudinal study that used interdisciplinary and comparative approaches, mixed-methods and triangulated data in order to document patterns of adaptation among 408 recently-arrived immigrant youth from Central America, China, the Dominican Republic, Haiti, and Mexico. The LISA study employed researchers and cultural advisors from multiple linguistic, cultural and academic backgrounds.

The Mexican and Central American youth were recruited in the San Francisco area from several public school districts. Schools in these districts were chosen because they had high 
densities of immigrant students. The LISA study focused on youth who had immigrated within five years prior to the first interview. Youth were required to have spent at least two-thirds of their lives in the country of origin. On average, 80 informants were recruited per cultural group, for a total of 408 students in the first year of the study. By the fifth year (academic year 2001/2002), the sample size was 309 , with an attrition rate of just under $25 \%$ (on average, $5 \%$ annually).

Bicultural, bilingual research assistants interviewed students who participated in the LISA study each year. Students completed interviews at school or after school, depending upon the participant's availability and the activities occurring at school on the day of the interview. All interviews were conducted on an individual basis, orally in the student's language(s) of choice. The interviews took from one and a half to two hours to administer and involved a variety of question formats (open-ended, fill-in-the-blank, Likert Scales, etc.). Students were reimbursed for their time and participation.

\section{Participants}

This study was limited to LISA participants born in Mexico $(n=76)$ and Central America $(n=63)$, all of whom were recruited from the San Francisco bay area. The students in this study sample were in grades four through eight and were between the ages of nine and 14 (mean age $=11.34, \mathrm{SD}=1.49$ ) in the first year of their participation (academic year 199798). During the third year of the study (the first year for which data are reported in this paper) the students were between the ages of 11 and 16. By the fifth and final wave of data collection (academic year 2001-02), students were between the ages of 14 and 19 and in grades seven through 12 . The sample was split almost evenly between girls $(n=71,51 \%)$ and boys $(n=68,49 \%)$. Power analyses that indicated that, with repeated measures on 139 students, it would be reasonable to expect power to be well over. 80 to detect an alpha of 05 .

The majority of the participants (68\% of the Central American and $78 \%$ of the Mexican youth) lived in families with two parental figures during the fifth and final year of the study. Forty-nine percent of the Central American and 20\% of the Mexican youth lived in households including aunts, uncles, cousins, and/or grandparents. During the course of the study, there was considerable fluctuation in household composition, with family members (including parents) regularly joining or leaving the household. Overall, household size averaged 6.40 people for Central American youth and 6.38 for Mexican youth. Seventeen percent of Central American mothers and 30\% of Mexican mothers had completed high school, compared with 24\% of Central American and 18\% Mexican fathers. More mothers were employed outside the home than fathers: Eighty-seven percent of Central American and $70 \%$ of Mexican participants' mothers worked outside the home (compared with $67 \%$ and $66 \%$ of their fathers, respectively). The two cultural groups shared similar income profiles. Seventy-five percent or more of household incomes from all groups clustered in the $\$ 10,000-\$ 50,000$ range. Roughly one quarter of the sample subsisted at the lowest income bracket (making under $\$ 20,000$ yearly).

\section{Measures}

The scales that were used in this study were derived from the LISA study's Behavioral and Relational Engagement measures, which were administered only during the third, 
fourth, and fifth years of the LISA study. As such, analyses were limited to these three years.

Support from Adults and Teachers at School Scale

The Support from Adults and Teachers at School Scale consisted of ten items that assessed students' perceptions of being supported by teachers and staff at school. Questions addressed both emotional and academic needs and included items such as "There is at least one adult in school I can always count on"; "If I have questions about schoolwork, I can count on someone there to help me"; and "Teachers do not treat me with respect" (reversed). Students were asked verbally whether the statement was generally true or false for them and then whether the statement was somewhat or very true/false. A 4-point Likert scale ranging from "Very True" to "Very False" was used. Negatively phrased items were reverse-coded, so that higher numbers corresponded with perceptions of higher support. Scores on all items were summed and then divided by the number of items answered, such that each student's full-scale score was any positive number ranging from 1.0 to 4.0. This approach (rather than the simple sum of items) allowed us to easily compare the effects of perceptions of support for each year with the effects of students' perceptions of support over several years. Reliabilities using Cronbach's alphas are as follows: Year $3 \alpha=.80$; Year $4 \alpha=.84$; Year $5 \alpha=.76$.

\section{Academic Engagement Scale}

The Academic Engagement Scale consisted of three items that asked about behaviors considered necessary for school success. Items included the following: Some students always finish their work BUT other students often do not finish it; Some students always turn in their homework on time BUT other students often do not turn in their homework on time; Some students pay close attention in class BUT other do not pay close attention in class. As in the Self-Perception Profile for Children/Adolescents (Harter, 1985, 1988), participants were asked whether they were more like the first or second group of students, then were asked whether the statement was "Really true" or "Sort of true" for them. Scores ranged from 1 to 4 on each item, with higher scores signifying higher engagement. Scores on all items were summed, such that the scale ranged from 3 to 12 . Reliabilities for the scale used in this study are as follows: Year $3 \alpha=.69$; Year $4 \alpha=80$; Year $5 \alpha=.73$.

\section{Results}

\section{Descriptive analyses}

Overall, students reported a high level of engagement (mean across years 1, 2, and $3=8.9, \mathrm{SD}=2.17)$. The sample mean of support across all years was $3.34(\mathrm{SD}=.38)$ with a range of 2.10 to 4.0. In general, students felt that their support experiences at school were more positive than negative, although they were not highly positive.

Independent sample $t$-tests were used to identify significant differences between groups of subjects on the dependent variables. Based on past literature, which has identified region of origin, age, gender, and level of schooling as factors predicting engagement and perceptions of support, these variables were tested for between group differences. Overall, $t$-tests showed few significant differences among groups of youth in the study. The 
youngest group of youth (ages 9 and 10 during the Year 1 of the LISA study) reported significantly higher engagement compared to youth ages 11 and 12 during Year 1. Youth who were in elementary school at Time 1 of the study reported higher engagement at Time 1, as compared to both middle and high school students, and higher engagement at Time 2, compared to youth in middle school (but not those in high school). When assessed as a control variable in the HLM analyses, age did not affect the overall pattern of findings.

\section{Attrition}

Over eighty percent (83.5\%) of the participants in this study completed the surveys at all three time points. Although the groups did not differ on most of the variables, noncompleters reported witnessing more violence at school. Study completion was thus entered into the base, predictive, and support varying models to determine its effects on growth curves of engagement and support. Attrition was unrelated to engagement, but was found to be associated with baseline support and changes in support over time (i.e., those who dropped from the study had higher baseline support and steeper declines in support). Attrition was thus assessed as a control variable in predictive HLM analyses involving support; this control did not affect the pattern of findings.

\section{Hierarchical linear modeling}

The HLM models developed here can be conceptualized as occurring at two levels. At level 1 , time-variant variables were entered to create a set of individual growth curves. At level 2, coefficients from the individual curves are aggregated to produce estimates of coefficients for the entire sample. Variables which remain constant, such as gender, average support across three years, and control variables (age and study completion) are added at the second level (see Raudenbush \& Bryk, 2002).

\section{Model 1: Base model}

To explore the first set of questions, an unconstrained base model was run. More specifically, our level 1 base model specified that:

Level 1.

$$
\text { Engagement }=\pi_{0}+\pi_{1}(\mathrm{TIME})+e
$$

The level 2 model uses the coefficients produced at level 1 to estimate group-level intercept and linear slope coefficients. Our unconstrained level 2 model reads:

Level 2.

$$
\begin{aligned}
& \text { Intercept : } \pi_{0}=\beta_{00}+\mu_{0} \\
& \text { Slope : } \pi_{1}=\beta_{10}+\mu_{1}
\end{aligned}
$$


The base model demonstrated reliable estimates of both intercept $(\tau=.375)$ and slope ( $\tau=.214)$. According to Bryk and Raudenbush (1987), reliability estimates greater than .05 are acceptable.

The first questions addressed by the base model concerned overall trends in the group as a whole. Contrary to expectations, on average there was no evidence of linear decline (or increase) in engagement during the three years studied. In other words, for the group as a whole, the slope of engagement was not significantly different from zero.

The second set of questions addressed by the base model concerned within-group variability in students' trajectories. Would most students in this study share similar trajectories or would there be a wide range of changes experienced over time? The variance components showed that there was indeed a significant degree of variability among students, both in their intercepts $(p<.001)$ and in their slopes, or rates of change $(p=.01)$. As such, while the group trend was one of little or no change over time, many individuals did experience changing levels of engagement during the three years studied.

From the variance components, it was apparent that students' trajectories of engagement could not be neatly summarized as static, declining, or increasing over time. From these statistics alone, however, it was not clear whether the apparent lack of change at the group level was driven by a large proportion of youth who reported stable engagement, or alternatively, whether those youth reporting increases in engagement over time "cancelled out" the decreases of reported by other youth.

We further addressed these questions using several strategies. First, we created a histogram of the slopes of engagement, which revealed an approximately normal curve of change over time (see Fig. 1). Thus, while one group of youth did hold constant over the three years, two other groups increased or decreased in engagement over time.

What accounted for these differing trajectories? The base model showed a high correlation between intercept and slope, meaning that youth's earlier engagement was associated with how their engagement changed over time. Interestingly, this correlation was negative $(\tau=-.720)$. As it was unclear whether this negative correlation stemmed from improvement among initially less engaged youth, decline among initially highly engaged youth, or both, supplementary analyses were performed to determine the dynamics

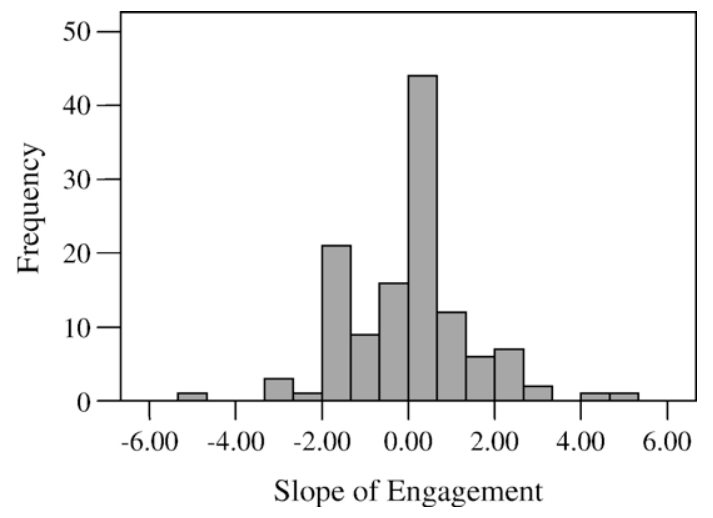

Fig. 1. Histogram of slopes of engagement. 
Table 1

Relationships between initial engagement and change in engagement over time

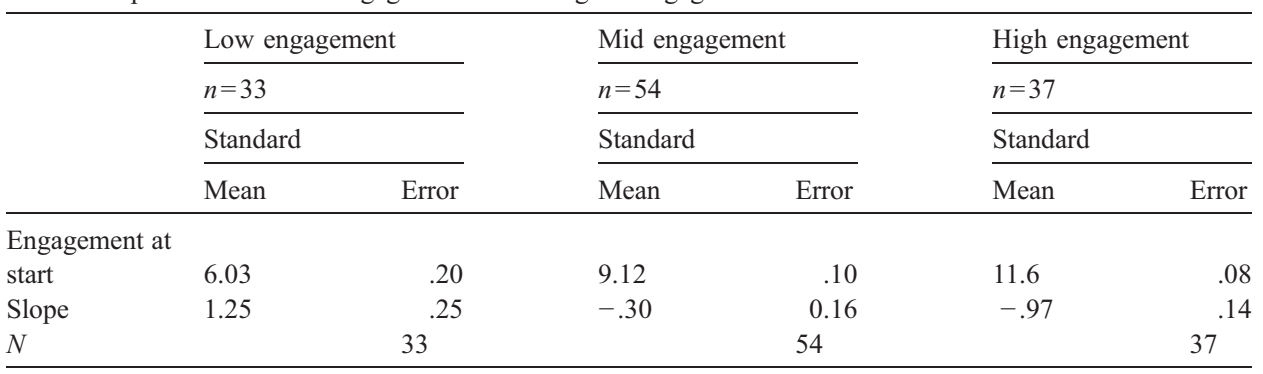

underlying the negative tau. Youth were divided into quartiles based on whether they reported lower (25th percentile and below), average (26th to 74th percentiles), or higher (75th percentile and above) engagement at Time 1. We then compared the slopes of engagement among these youth and found that youth who started off more engaged were in fact more prone to experience declines over time, while those who started off less engaged were more likely to improve over time. Youth who reported average levels of engagement at Time 1 tended to fall into the mid-range of engagement over time (see Table 1).

Although a number of factors might explain the negative relationship between intercept and slope (including floor and ceiling effects and regression to the mean), other factors, including support, were also hypothesized to play a role in these associations.

\section{Model 2: Predictive model}

Next, relationships among engagement, gender, and perceptions of school support were explored. In particular, our analyses were aimed at determining whether boys and girls in our sample reported similar levels of engagement at Time 1 and similar patterns of change over time. We were also interested in assessing how students' perceptions of support related to their engagement trajectories (i.e., whether higher levels of support were accompanied by higher initial engagement and more positive change over time). Finally, we sought to determine how perceptions of support related to boys' versus girls' engagement.

To address these questions, the base model was expanded by incorporating gender, perceptions of support (the mean of support over the three years), an interaction term (gender*mean support), and attrition (study completion) into the level 2 equations as predictors. ${ }^{1}$ The predictive model was specified as follows:

Level 1.

$$
\text { Engagement }=\pi_{0}+\pi_{1}^{*}(\mathrm{TIME})+e
$$

\footnotetext{
${ }^{1}$ We used an effects-coding scheme to model the interaction, with $1=$ girls and $-1=$ boys. The positive coefficient of gender for slope signifies that girls' slopes tended to be more positive (or less negative), relative to the mean of all slopes; it does not necessarily predict that the slope of engagement is positive for girls and negative for boys (i.e.: that engagement increases over time for girls and decreases for boys).
} 
Level 2.

$$
\begin{aligned}
& \text { Intercept : } \pi_{0} \beta_{00}+\beta_{01} *(\text { GENDER })+\beta_{02} *(\text { MEAN SUPPORT }) \\
& +\beta_{03} * \text { (GENDER } * \text { MEAN SUPPORT) } \\
& +\beta_{04} *(\text { STUDY COMPLETION })+\mu_{0} \\
& \text { Slope : } \pi_{1}=\beta_{10}+\beta_{11} *(\text { GENDER })+\beta_{12} *(\text { MEAN SUPPORT }) \\
& +\beta_{13} *(\text { GENDER } * \text { MEAN SUPPORT) } \\
& +\beta_{13} *(\text { STUDY COMPLETION })+\mu_{1}
\end{aligned}
$$

As shown in Table 2, which presents the fixed effects with robust standard errors, $p$-values, and effect sizes for our predictive model, gender was significantly related to the intercept of engagement, as expected ( $p=.03)$. Contrary to the hypotheses, however, boys reported higher engagement at Time 1, as conveyed by the negative coefficient for the intercept of gender. Interestingly, however, the gender coefficient for slope was positive ( $p=.03$ ), with girls reporting more positive changes in engagement over time, relative to boys. Questions about the relationship between perceptions of support and engagement also produced some findings. Specifically, perceptions of support tended to be positively related to youths' initial engagement, with higher levels of mean support marginally associated with higher initial engagement $(p=.06)$. Given the effect sizes (all greater than or equal to .15), these findings suggest a connection between perceptions of support and academic engagement.

Examination of the interaction terms suggested that gender might play a role in how perceptions of support shape academic engagement trajectories. In order to interpret and depict gender-by-support relationships, the coefficients produced by HLM were entered into the two level 2 equations from the predictive model, allowing mean support to vary.

Figs. 2 and 3 show that while support is associated with engagement for both boys and girls in the sample, it appears to predict different aspects of youths' engagement trajectories, depending on gender. For girls, higher levels of support predicted higher initial engagement

Table 2

Predictive model

\begin{tabular}{lccccc}
\hline & Coefficient & Standard error & $d . f$. & $p$-value & Effect size \\
\hline Initial engagement & & & & & \\
Intercept & 7.58 & .99 & 131 & $>.001$ & .55 \\
Gender & -4.66 & 2.11 & 131 & .03 & .18 \\
Mean support & 1.21 & .65 & 131 & .06 & .16 \\
Mean support*Gender & 1.28 & .64 & 131 & .05 & .17 \\
Study completion & 1.56 & 1.03 & 131 & .13 & - \\
& & & & & \\
Slope & .44 & .51 & 131 & .38 & - \\
Intercept & 2.16 & .96 & 131 & .03 & .19 \\
Gender & .43 & .28 & 131 & .13 & - \\
Mean support & -.62 & .28 & 131 & .03 & .19 \\
Mean support*Gender & -.55 & .52 & 131 & .29 & - \\
Study completion & & & & & \\
\hline
\end{tabular}




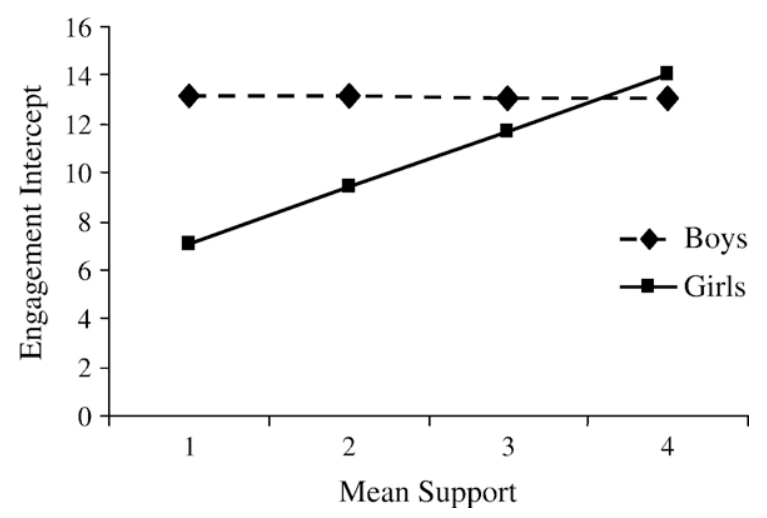

Fig. 2. Support by gender interaction for initial engagement.

$(p=.05)$. For boys, support had no effect on initial engagement, but predicted positive changes in engagement over time $(p=.03)$. Using the original data, correlations supported these findings: Time 1 engagement and mean support were significantly correlated for girls $(p<.05)$ but not boys, while the correlation between the slope of engagement and mean support was marginally significant for boys $(p=.06)$ but not girls $(p>.05)$.

Model 3: Support-varying over time

In the final model, the relationship between support and engagement was investigated again. Whereas the predictive model focused on relationships between engagement and fixed levels of support (the mean for each youth across all time periods), the third model focused on relationships between engagement and time-varying perceptions of support. Here, fluctuations in support were modeled in a student-centered manner, acknowledging that perceptions of support relative to one's own expectations and past experiences may be especially critical in shaping engagement.

To address these aims, a support-varying model with the following set of equations was created.

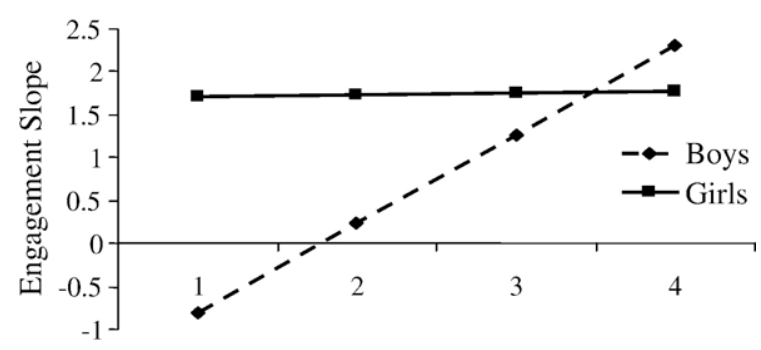

Mean Support

Fig. 3. Support by gender interaction for change in engagement over time. 
Table 3

Support varying over time

\begin{tabular}{lccccc}
\hline Predictors of engagement & Coefficient & Standard error & d.f. & $p$-value & Effect size \\
\hline Intercept & 9.03 & .26 & 135 & $>.001$ & .95 \\
Time & -.094 & .112 & 135 & .470 & - \\
& & & & & \\
Support & 4.24 & 1.05 & 351 & $>.001$ & .21 \\
Intercept & -3.26 & 1.15 & 351 & .006 & .15 \\
Study completion & & & &
\end{tabular}

Level 1.

$$
\text { Engagement }=\pi_{0}+\pi_{1} *(\mathrm{TIME})+\pi_{2} *(\mathrm{SUPPORT})+e
$$

Level 2.

$$
\begin{aligned}
& \text { Intercept : } \pi_{0}=\beta_{00}+\mu_{0} \\
& \text { Slope : } \begin{aligned}
\pi_{1} & =\beta_{10}+\mu_{1} \\
\pi_{2} & =\beta_{20}+\beta_{21} *(\text { STUDYCOM })+\mu_{2}
\end{aligned}
\end{aligned}
$$

In this model, perceived support for each year was entered as a level 1 predictor. Support was centered around each individual's mean such that this variable represented annual fluctuations in perceived support occurring at the individual level. ${ }^{2,3}$ As in the two previous models, the support-varying model produced reasonably reliable estimates of both intercept and slope (intercept, $\tau=.34$; slope, $\tau=.15$ ). Again, time was not a significant predictor of engagement. However, increases or decreases in support, relative to each individual's average support, were robust predictors of engagement levels $(p<.001)$, even after controlling for the effects of study completion $(p=.006)$. The coefficient for support was positive-youth who reported higher levels of support relative to their personal means were also more likely to report higher levels of engagement in that same year. Those reporting less support than their own averages were more likely to report lower engagement in that year (see Table 3).

These results demonstrate that while students' perceptions of support do not follow a linear course over time, such perceptions do change from year to year and even minor changes predict engagement levels. In other words, while students did not consistently decline or increase in perceived support over time, they did report fluctuations in their perceptions of support as they progressed through school. Furthermore, when youth

\footnotetext{
${ }^{2}$ Unfortunately, it was not possible to include the error term for the coefficient of the intercept, time, and support concurrently in our final model, due to limited degrees of freedom. To assess error for intercept, time, and support, error terms were included for intercept and time while excluded for support, then included for time and support while excluded for intercept.

${ }^{3}$ While causality cannot be determined from this data and our methods, reverse models predicting support from engagement (both including and excluding gender) were run and found to be a poor fit for the data.
} 
Engagement Varying with Support

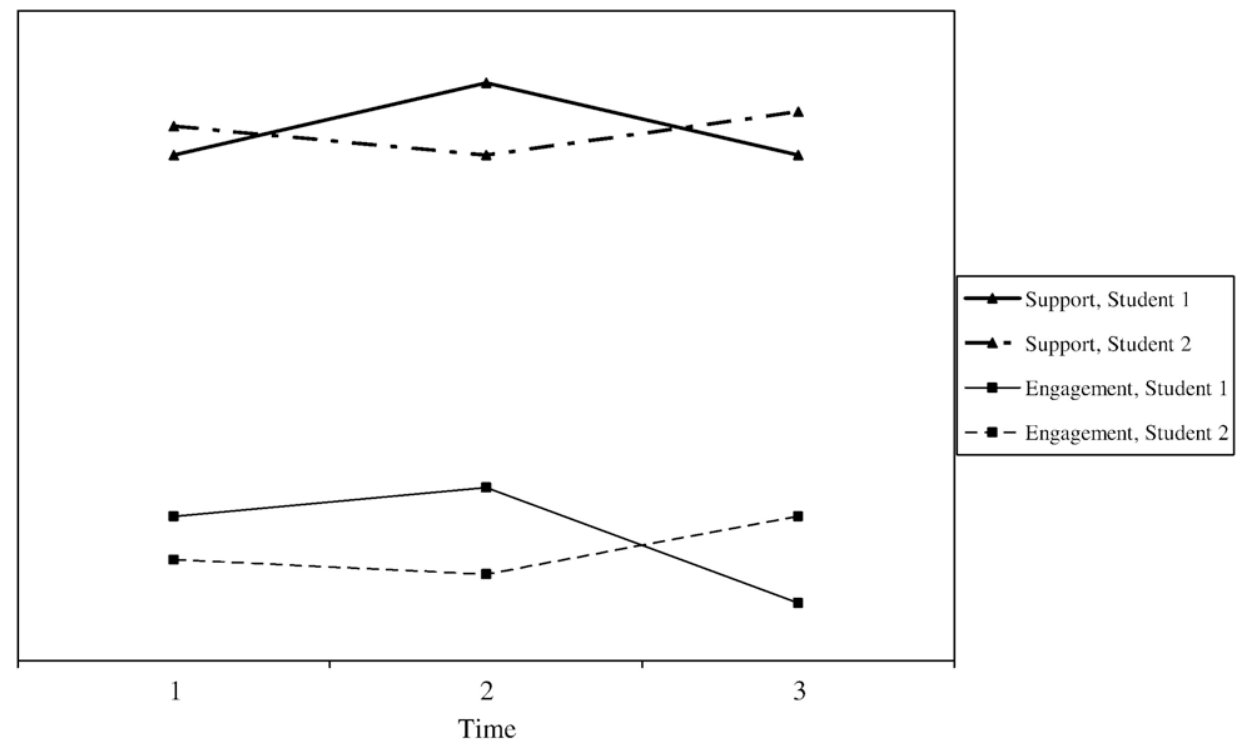

Fig. 4. Relationship between changes in support and engagement.

experienced more support relative to their own baseline, they were more engaged. In other words, support and engagement appear to increase and decrease in tandem.

This relationship is best depicted by looking at individuals' growth curves. Fig. 4 shows the actual engagement and support scores of two students who were randomly selected with the sole criteria of identical mean support scores. As is clear from the figures, while these two students reported the same average level of support (3.67) over the three years of the study, they differed in how they arrived at this number. Student 1 reported higher, lower, and then higher support and Student 2 reported an opposite pattern of support (lowerhigher-lower). As is portrayed by the plots of their engagement and support scores, for both youth, increases in support were accompanied by increases in engagement, while decreases in support corresponded with decreases in engagement.

\section{Discussion}

A central aim of this study was to describe the academic engagement trajectories of recently arrived immigrant youth from Mexico and Central America, including factors associated with within-group and within-student variation. Initial engagement, gender, and support from adults at school were investigated as shaping youths' engagement over time. The findings from the base model revealed that engagement among these Latin American immigrant youth is by no means static over time, nor is change uniform across individuals. Instead, consistent with previous findings with a larger sample, (Suárez-Orozco et al., 2007) over the course of three years the students in this study reported a range of engagement trajectories - some showed improvements; some showed declines; and others held steady. 
Because of this high degree of variation, the simple averaging of trajectories can result in the loss of critical information about the breadth of individual experiences.

To a large extent, research on Latin American youth using quantitative methods has not sufficiently attended to such individual variation. Most often, studies of this population have depicted group-level declines in engagement over time. By contrast, qualitative research has profited from person-centered methods which have depicted the diversity and complexity in engagement pathways among Latin American immigrant youth (Conchas, 2001). Our findings demonstrate the need for mixed methods approaches and statistical models that incorporate the benefits of large-scale, longitudinal quantitative studies with the attention to individual pathways more common in qualitative research approaches (Raudenbush \& Bryk, 2002).

In our second model, we investigated the influence of time-independent factors on school engagement trajectories. Gender and mean support emerged as important predictors of youths' engagement trajectories, both alone and through interactions. Boys were more highly engaged at Time 1, but also tended to have steeper declines in engagement over time relative to girls. Girls became more engaged than boys over time. In addition, the relationships between the average amount of school-based support perceived over three years and youths' engagement differed somewhat for boys and girls. For girls, support was positively associated with initial engagement, whereas for boys, it was positively associated with changes in engagement.

Researchers have shed light onto some of the circumstances and processes that potentially underlie the interactions between gender and support. For example, previous research has depicted girls as more reactive to their initial perceptions of support and evaluations from others (Batgos \& Leadbeater, 1994). Over time, however, boys and girls may differ in their responsiveness to school support, especially as developmental and acculturative processes ensue. As such, some have argued that Latin American immigrant girls hold social advantages over their male counterparts (Cammarota, 2004; Lopez, 2002). Thus, low support may exacerbate other risks experienced by boys, while highly supportive relationships with school adults may become especially salient over time. Indeed, although some have implied that boys are less oriented toward their teachers, research has also shown that boys of Latin American descent may be more likely to be responsive to school environment factors, including the student body composition and school climate (Rodriguez, 2003). Likewise, some research shows that boys may benefit more from teacher connection and teacher caring, although they may be less likely to experience such highly supportive relationships (Furrer \& Skinner, 2003; Way \& Chu, 2003).

Interventions that normalize help seeking and connect youth with mentors and other positive role models may be critical for Latin American immigrant youth, especially boys. Given the importance of peer relationships, especially in adolescence, group-focused interventions might be especially effective among these youth. In addition, further research addressing the longitudinal dimensions of the impact of school support is necessary to better understand how these dynamic processes unfold in gendered contexts.

In the final model, the support-varying model, all available support scores for each youth were entered into the equations, which permitted support to change from year to year within-person. Relationships between changes in support and engagement were then 
examined. Rather than adhering to linear trajectories, perceptions of support fluctuated from year to year, and these fluctuations were linked to youths' engagement in school that year. During a year when youth experienced an above average amount of support (relative to him or herself), he or she also reported higher engagement. In contrast, a less than average support year was associated with lower engagement that year. Thus, for the individuals in this study, support and engagement rose and fell together.

These findings suggest a dynamic association between support perceptions and engagement and lend empirical support to what parents and educators have long observed - that students' motivation and effort in school correspond with their current connections with their teachers. A student may experience a good fit with his or her teachers one year, and then a less than ideal fit the next year. This study's findings therefore suggest that support perceptions are fixed neither in persons nor in time. Although previous researchers have investigated associations between changes in school environments and changes in psychological and academic functioning, they have generally focused on linear patterns attributable to other broader changes such as school transitions and developmental shifts (Eccles, Wigfield, Midgley, \& Reuman, 1993; Reddy, Rhodes \& Mulhall, 2003; Seidman, Aber, Allen, \& French, 1996). The findings from this study highlight the need for dynamic approaches to studying students' adaptation over time.

Taken together, the findings from this study also raise questions about popular approaches to conceptualizing risk and resilience. Traditionally, researchers often use single time-point data to categorize youth as "resilient" or "at-risk," implying that resilience and risk are stable over time, embedded in the individual, and mutually exclusive. According to this study's findings, baseline engagement is not inexorably linked to later engagement, nor are perceptions of support constant over time. The findings from this study thus echo those of Egeland, Carlson, and Sroufe (1993) and Pianta and Walsh (1998), who demonstrated that adaptation is flexible to changing circumstances over time and influenced by multiple systems. Initial engagement, changes in engagement, and perceptions of support appear to result from multiple interacting risk and protective factors which themselves vary over time.

There are several limitations to this study that bear mentioning. Support and engagement observations were measured contemporaneously each year, limiting our ability to make inferences regarding causality. For example, the relationship between increased support and higher engagement (or alternatively, decreases in support and lower engagement) likely go both ways. While post-hoc analyses indicated that reverse models were a poor fit for the data (see endnote 3 ), it is likely that those who are more engaged may also be more likely to view adults in a positive light, while those who are less engaged may have relational difficulties that extend beyond school grounds.

On a similar note, our analyses depended on adolescents' subjective perceptions of school-based support, which may not necessarily map onto actual amounts that were enacted or more concrete markers of support. Nonetheless, several studies have shown that individuals' reports of how much support would be available to them if needed (i.e., perceived support) are more consistently related to positive outcomes than support actually received (Kessler \& McLeod, 1985). As discussed earlier, these perceptions are likely to be shaped by dynamically interacting factors, including students' attachment histories, 
emotional wellbeing, social intelligence, and current school environments (Lakey \& Dickenson, 1994). Future studies should track changing perceptions of both parental and teacher relationships to help decipher the extent to which school-based relationships contribute unique variance to student adjustment.

It is also worth noting that participants were all recently arrived immigrant youth, whereas the bulk of past immigration research has focused on mixed generations of youth. Moreover, since this study focused on Latin American immigrant youth who settled in urban areas and who were mostly of low SES, the findings may not reflect the experiences of those youth who reside in suburban or rural areas and who are economically more privileged. This study also did not closely examine possible differences between the Mexican and Central American youth (although few baseline differences in main variables were found). The two groups vary in their sending circumstances and may differ in their receipt of support and receptiveness to support from non-familial adults. Similarly, although few baseline differences were found among the groups, variability in other factors, including family constellation, could have affected pattern of findings.

This study relied on self-report measures, which may not have aligned with other indicators of academic adjustment (such as GPA or standardized tests). Moreover, academic engagement was operationalized with only three items, the reliability of which was somewhat lower than the ideal. Although previous studies have found that students' scores on this scale were highly correlated with teacher's reports of the students' academic engagement (Suarez-Orozco, Milburn, \& Rhodes, 2006) and with students' completion of school work (Suárez-Orozco et al., 2007), additional measures of school adaptation would have greatly strengthened this study.

Students' response styles and inclinations to report positive academic adjustment and perceptions of support may have also factored into these findings. While efforts to address some of these limitations were made in the support-varying model, the number of waves of data prohibited us from examining all error terms at once. Moreover, this study did not examine how students' perceptions of support and engagement vary from school to school or class to class and instead asked students to summarize their engagement and perceptions of support. To some extent, this assessment approach was in keeping with ecological reality of American middle and high schools, where students transition through multiple classes throughout the school day. Nonetheless, it will be important to examine both the effects of particular relationships as well as the larger school contexts in which those relationships. Future studies might use three-level models to address these issues. Similarly, this study relied on three time points to examine change over time, precluding examination of nonlinear (i.e., quadratic) trajectories. Other modeling approaches, including structural equation modeling, could also be incorporated to examine predictive hypotheses about the directionality of relationships between engagement and support. For example, improvements in academic performance might account for increased attention and support from adults and as well as higher future engagement.

These limitations notwithstanding, the findings from this study have both theoretical and practical implications. They suggest that a student's "at risk" status can change over time and is affected by other time-varying factors, including perceptions of support. Moreover, the findings indicate that caring adults within the school setting may offer some protection against vulnerable students' academic disengagement. As such, schools should consider 
ways to increase opportunities for supportive relationships to emerge. Policies that ensure more contact and continuity with teachers, such as homerooms, advising and multi-year teaching assignments, might be helpful in this regard. Within this context, resources should be deployed that enhance student-teacher fit such that the student feels supported and the teacher feels effective. As these finding suggest significant variation from year to year, it is important that every year the connections of students be assessed, established, and reinforced. Practices that enrich student-teacher relationships might go a long way toward enhancing the well being of the growing number of Latin American immigrant students in American schools.

\section{References}

Batgos, J., \& Leadbeater, B. J. (1994). Parental attachment, peer relations and dysphoria in adolescence. In M. Sperling \& W. H. Berman (Eds.), Attachment in adults: Clinical and developmental perspectives (pp. 155-178). New York: Guilford Press.

Brewster, A., \& Bowen, G. L. (2004). Teacher support and the school engagement of Latino middle and high school students at risk for school failure. Child \& Adolescent Social Work Journal, 21(1), 47-67.

Bryk, A. S., \& Raudenbush, S. W. (1987). Application of hierarchical linear models to assessing change. Psychological Bulletin, 101(1), 147-158.

Cammarota, J. (2004). The gendered and racialized pathways of Latina and Latino Youth: Different struggles, different resistances in the urban context. Anthropology \& Education Quarterly, 35(1), 53-74.

Catterall, J. S. (1998). Risk and resilience in student transitions to high school. American Journal of Education, 106(2), 302-333.

Census, U.S. (2000). U.S. Bureau of the Census. http://www.census.gov/

Coll, C. G., Crnic, K., Lamberty, G., \& Wasik, B. H. (1996). An integrative model for the study of developmental competencies in minority children. Child Development, 67(5), 1891-1914.

Conchas, G. Q. (2001). Structuring failure and success: understanding the variability in Latino school engagement. Harvard Educational Review, 71(3), 475-504.

Cooper, C. R., Denner, J., \& Lopez, E. M. (1999). Cultural brokers: Helping Latino children on pathways toward success. Future Child, 9, 51-57.

Croninger, R. G., \& Lee, V. E. (2001). Social capital and dropping out of high school: benefits to at-risk students of teachers' support and guidance. Teachers College Record, 103(4), 548-581.

Davison Aviles, R. M., Guerrero, M. P., Barajas Howarth, H., \& Thomas, G. (1999). Perceptions of Chicano/Latino students who have dropped out of school. Journal of Counseling \& Development, 77(4), 465-473.

Eccles, J. S., Wigfield, A., Midgley, C., \& Reuman, D. (1993). Negative effects of traditional middle schools on students' motivation. Elementary School Journal, 93(5), 553-574.

Egeland, B., Carlson, E., \& Sroufe, A. (1996). Resilience as process. Development and psychopathology: Cambridge University Press. Falbo, T. (1996). Latino youth and high school graduation.

Fry, R. (2003). Hispanic youth Dropping out of U.S. schools: Measuring the challenge. http://www.pewtrusts.com/ pdf/vf_pew_hispanic_dropout.pdf

Fuligini, A., \& Pederson, S. (2002). Family obligation and the transition to young adulthood. Developmental Psychology, 38(5), 856-868.

Furrer, C., \& Skinner, E. (2003). Sense of relatedness as a factor in children's academic engagement and performance. Journal of Educational Psychology, 95(1), 148-162.

Garcia-Coll, C., Szalacha, L., \& Palacios, N. (2005). Children of Dominican, Portuguese, and Cambodian Immigrant Families: Academic pathways during middle childhood. In C. Cooper, C. Garcia-Cull, T. Barton, H. Davis, \& C. Chatman (Eds.), Developmental pathways through middle childhood: Rethinking contexts and diversity as resources. Mahwah, NJ: Erlbaum Associates.

Hamre, B. K., \& Pianta, R. C. (2001). Early teacher-child relationships and the trajectory of children's school outcomes through eighth grade. Child Development, 72, 625-638.

Harter, S. (1985). The self-perception profile for children: Revision of the perceived competence scale for children. Denver, CO: University of Denver. 
Harter, S. (1988). Manual for the adolescent self-perception profile. Denver, CO: Author.

Hernandez, D. J. (2004). Demographic change and the life circumstances of immigrant families. The Future of Children, Special Issue on Children of Immigrants, 14, 16-47.

Hudley, C., Daoud, A., Polanco, T., Wright-Castro, R., \& Hershberg, R. (2003). Student engagement, school climate and future expectations in high school. Biennial meeting of the society for research in child development. Tampa, FL.

Kao, G., \& Tienda, M. (1998). Educational aspirations of minority youth. American Journal of Education, 106(3), 349-384.

Katz, S. R. (1999). Teaching in tensions: Latino immigrant youth, their teachers and the structures of schooling. Teachers College Record, 100(4), 809-840.

Kessler, R. C., \& McLeod, J. D. (1985). Social support and mental health in community samples. In Cohen \& Syme (Eds.), Social support and health. (pp. 219-240). New York, NY: Academic Press.

Lakey, B., McCabe, K. M., Fisicaro, S. A., \& Drew, J. B. (1996). Environmental and personal determinants of support perceptions: Three generalizability studies. Journal of Personality and Social Psychology, 70, 1270-1280.

Lopez, N. (2002). Rewriting race and gender high school lessons: Second-generation Dominicans in New York City. Teachers College Record, 104(6), 1187-1203.

Losey, K. M. (1995). Mexican American students and classroom interaction: An overview and critique. Review of Educational Research, 65(3), 283-318.

Lowell, B. L., \& Suro, R. (2002). The improving educational profile of Latino immigrants. http://www.coe.uga. edu/clase/resources/Pew\%20Ed\%20Profile\%20Latinos.pdf

Lutz, C. J., \& Lakey, B. (2001). How people make support judgments: Individual differences in the traits used to infer supportiveness in others. Journal of Personality and Social Psychology, 81, 1070-1079.

McMillan, J. H. (1997). Dropout rates in the United States: 1995.

Ogbu, J. U. (1991). Minority coping responses and school experience. Journal of Psychohistory, 18(4), 433-456.

Pianta, R. C. (1999). Enhancing relationships between children and teachers. Washington, D.C.: American Psychological Association.

Pianta, R. C., \& Walsh, D. J. (1998). Applying the construct of resilience in schools: Cautions from a developmental systems perspective. Psychology Review, 27, 407-417.

Pianta, R. C., Steinberg, M., \& Rollins, K. (1995). The first two years of school: Teacher-child relationships and deflections in children's classroom adjustment. Development of Psychology, 7, 295-312.

Pierce, T., \& Lydon, J. (2001). Global and specific relational models in the experience of social interactions. Journal of Personality and Social Psychology, 80(4), 613-631.

Portes, P. R. (1999). Social and psychological factors in the academic achievement of children of immigrants: A cultural history puzzle. American Educational Research Journal, 36(3), 489-507.

Portes, A. (2000). The two meanings of social capital. Sociological Forum, 15, 1-12.

Portes, A., \& Rumbaut, R. G. (2001). Legacies: The story of the second generation. Berkeley: University of California Press.

Raudenbush, S. W., \& Bryk, A. S. (2002). Hierarchicical linear models: Applications and data analysis methods (2nd Edition ed.). Thousand Oaks, CA: Sage Publications.

Reddy, R., Rhodes, J., \& Mulhall, P. (2003). The influence of teacher support on student adjustment in the middle school years: A latent growth curve study. Development and Psychopathology, 15, 119-138.

Roderick, M. (2003). What's happening to the boys? Early high school experiences and school outcomes among African American male adolescents in Chicago. Urban Education, 38(5), 538-607.

Rodriguez, T. D. (2003). School social context effects on gender differences in academic achievement among second-generation Latinos. Journal of Hispanic Higher Education, 2(1), 30-45.

Roffman, J., Suárez-Orozco, C., \& Rhodes, J. (2003). Facilitating positive development in immigrant youth: The role of mentors and community organizations. In D. Perkins, L. M. Borden, J. G. Keith, \& F. A. Villarreal (Eds.), Positive youth development: Creating a positive tomorrow. Brockton, MA: Klewer Press.

Romero, A. J., \& Roberts, R. E. (2003). Stress within a bicultural context for adolescents of Mexican descent. Cultural Diversity \& Ethnic Minority Psychology, 9(2), 171-184.

Rumbaut, R. G. (1994). The crucible within: ethnic identity, self-esteem and segmented assimilation among children of immigrants. International Migration Review, 28(4), 748-794.

Ryan, A. M., \& Patrick, H. (2001). The classroom social environment and changes in adolescents' motivation and engagement during middle school. American Educational Research Journal, 38(2), 437-460. 
Seidman, E., Aber, J. L., Allen, L., \& French, S. E. (1996). The impact of the transition to high school on the selfesteem and perceived social context of poor urban youth. American Journal of Community Psychology, 24(4), $489-515$.

Stanton-Salazar, R. D. (2001). Manufacturing hope and despair: The school and kin support networks of U.S.-Mexican youth. Teachers College Press.

Stanton-Salazar, R. D., Chavez, L. F., \& Tai, R. H. (2001). The help-seeking orientations of Latino and non-Latino urban high school students: A critical-sociological investigation. Social Psychology of Education, 5(1), 49-82.

Stanton-Salazar, R. D., \& Spina, S. U. (2003). Informal mentors and role models in the lives of urban Mexicanorigin adolescents. Anthropology \& Education Quarterly, 34(3), 231-254.

Suárez-Orozco, M. M. (1987). "Becoming somebody": Central American immigrants in U.S. inner-city schools. Anthropology \& Education Quarterly, 18(4), 287-299.

Suárez-Orozco, C. (2000). Identities under siege: Immigration stress and social mirroring among the children of immigrants. In A. Robben \& M. Suárez-Orozco (Eds.), Cultures under siege: Social violence \& trauma. Cambridge: Cambridge University Press.

Suárez-Orozco, C., Qin-Hilliard, D. B., Way, N., \& Chu, J. Y. (2004). Immigrant boys' experiences in U.S schools immigrant boys' experiences in U.S. schools. Adolescent boys: Exploring diverse cultures of boyhood (pp. 295-316). New York University Press.

Suárez-Orozco, C., \& Suárez-Orozco, M. M. (2001). Children of immigration. Cambridge, MA: Harvard University Press.

Suárez-Orozco, C., Suárez-Orozco, M., \& Todorova, I. (2007). Learning a new land: Immigrant students in American society. Cambridge, MA: Harvard University Press.

Valenzuela, A. (1999). Subtractive schooling: U.S.-Mexican youth and the politics of caring. State University of New York Press.

Valenzuela, A., Jr. (1999). Gender roles and settlement activities among children and their immigrant families. American Behavioral Scientist, 42(4), 720-742.

Velez, W. (1989). High school attrition among Hispanic and non-Hispanic White youths. Sociology of Education, 62(2), 119-133.

Vernez, G., \& Abrahamse, A. (1996). How immigrants fare in U.S. education.

Way, N., \& Chu, J. Y. (2003). Adolescent boys. New York: NYU Press.

White, M. J., \& Kaufman, G. (1997). Language usage, social capital and school completion among immigrants and native-born ethnic groups. Social Science Quarterly, 78(2), 385-398. 